\title{
Experimental Research and Finite Element Analysis on Mechanical Property of SFRC T-Beam
}

\author{
Min Sun, ${ }^{1}$ Jiapeng $Z \mathrm{Zhu}^{1}{ }^{1}$ Ning $\mathrm{Li},{ }^{1}$ and C. C. Fu ${ }^{2}$ \\ ${ }^{1}$ Department of Civil Engineering, Suzhou University of Science and Technology, Suzhou, Jiangsu 215011, China \\ ${ }^{2}$ University of Maryland at College Park, College Park, MD 20742, USA \\ Correspondence should be addressed to Min Sun; sunmin@mail.usts.edu.cn
}

Received 23 January 2017; Accepted 14 March 2017; Published 4 May 2017

Academic Editor: Peng Zhang

Copyright (c) 2017 Min Sun et al. This is an open access article distributed under the Creative Commons Attribution License, which permits unrestricted use, distribution, and reproduction in any medium, provided the original work is properly cited.

\begin{abstract}
Research on mechanical property of SFRC was done through experiments of two SFRC T-beams and one concrete T-beam, while the influences of different volume fractions of steel fibers on integral rigidity, ultimate shear capacity, and the crack distribution characteristics were analyzed. ANSYS finite element software was used to simulate the tests and it was found that there was good conformation between the results of ANSYS simulation and tests. The test results and finite element software simulation both showed that the incorporation of steel fibers in the concrete can increase the integral rigidity and ultimate shear capacity, while partially reducing the propagation of cracks effectively. It was also proved that it is reliable to simulate SFRC T-beam by ANSYS software.
\end{abstract}

\section{Introduction}

T-beam is very commonly used in the Chinese highway bridges, where the crackle status is very serious in T-beams. With the wide usage of the traditional concrete, some obvious shortcomings are exposed gradually, such as low strength, poor ductility, and the brittle failure under the impact load. These shortcomings will limit the application of concrete in the future structure. If some steel fibers are added in concrete, fiber can not only prevent the development of concrete cracks but also improve the flexural, shear, and tensile properties of concrete [1-4]. At the same time, steel fibers can improve the antifatigue, anti-impact, durability, and crack toughness of concrete $[5,6]$ and make concrete sustain certain plastic properties.

Steel fiber reinforced concrete (SFRC) has a good crack resistance, so it is widely used in the fields of airport pavement, bridge deck, and waterproof roof. But now there are not a lot of researches on the shear performance and crack resistance effect of SFRC T-beam. In this paper, a concrete T-beam and two SFRC T-beam specimens were designed to investigate the effect of steel fiber content on the bearing capacity of concrete T-beam to understand the characteristics of SFRC in shear and crack resistance.

\section{Preparation of Test}

2.1. Description of Specimens. In this test, three test T-beams were prepared, one three-meter (length) ordinary concrete T-beam and two three-meter (length) SFRC T-beams. The parameters of specimen are shown in Table 1. HRB335 steel bar was used as the tension longitudinal reinforcement, while HPB235 steel bar was used as the compression longitudinal reinforcement, the flange plate main bars, and the stirrups. The section size and reinforcement layout are shown in Figure 1.

2.2. Materials Properties. In this experiment, a tape of waved steel fibers produced by Suzhou Longyu Co., Ltd., with $792 \mathrm{MPa}$ tensile strength, $30.18 \mathrm{~mm}$ fiber length, $0.91 \mathrm{~mm}$ equivalent diameter, and 33-aspect ratio, was used. The mechanical properties of concrete and the reinforced bar are shown in Tables 2 and 3.

2.3. Test Method. In the test, the method of two-point loading was used by the distributive beam. The shear span ratio was 2. The support of the beam was $225 \mathrm{~mm}$ far from the beam end, and the loading device was a separate type of hydraulic 
TABLE 1: Test T-beam parameters.

\begin{tabular}{lcccr}
\hline Material & Beam node & $\begin{array}{c}\text { Stirrup spacing } \\
(\mathrm{mm})\end{array}$ & Stirrup ratio & $\begin{array}{c}\text { Volume fraction of } \\
\text { steel fiber }\end{array}$ \\
\hline Concrete & 1 & 150 & $0.48 \%$ & 0 \\
SFRC & 2 & 150 & $0.48 \%$ & $\rho=1.5 \%$ \\
SFRC & 3 & 150 & $0.48 \%$ & $\rho=2.0 \%$ \\
\hline
\end{tabular}

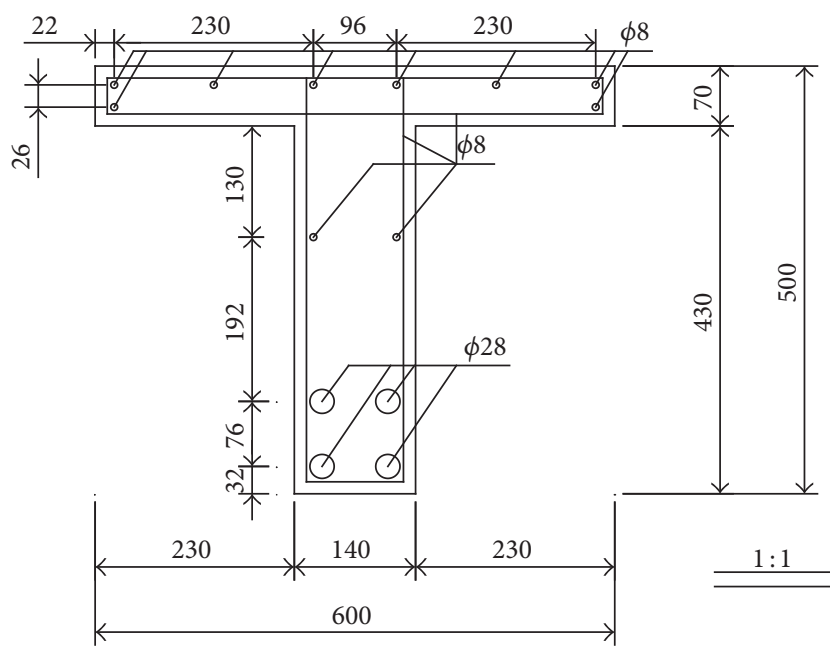

FIGURE 1: Section size and reinforcement layout (unit: $\mathrm{mm}$ ).

TABLE 2: Mechanical properties of concrete.

\begin{tabular}{lccc}
\hline Beam node & $\begin{array}{c}\text { Crushing } \\
\text { compressive } \\
\text { strength }\end{array}$ & $\begin{array}{c}\text { Concrete } \\
\text { compressive } \\
\text { strength }\end{array}$ & $\begin{array}{c}\text { Young's } \\
\text { modulus }\end{array}$ \\
\hline 1 & 37.1 & 28.2 & 31.9 \\
2 & 40.3 & 30.6 & 32.7 \\
3 & 40.5 & 30.8 & 32.7 \\
\hline
\end{tabular}

TABLE 3: Mechanical properties of reinforced bar.

\begin{tabular}{lcccc}
\hline Steel grade & $\begin{array}{c}\text { Bar } \\
\text { diameter }\end{array}$ & $\begin{array}{c}\text { Yield } \\
\text { stress }\end{array}$ & $\begin{array}{c}\text { Ultimate } \\
\text { stress }\end{array}$ & $\begin{array}{c}\text { Young's } \\
\text { modulus }\end{array}$ \\
\hline HPB235 & 8 & 342 & 500 & 210 \\
HRB235 & 28 & 389 & 574 & 200 \\
\hline
\end{tabular}

Note. In Tables 2 and 3, length unit is $\mathrm{mm}$, the strength unit is Mpa, and Young's modulus unit is Gpa.

jack that used a high-precision static servo-hydraulic-control system. Gradation loading was acted on the beam, and the holding time was 15 minutes. In the process of loading, the crack occurrence and development should be carefully observed.
TABLE 4: Summary of shear resistance of beams.

\begin{tabular}{lccc}
\hline Beam node & $V \mathrm{cr}(\mathrm{KN})$ & $V \mathrm{u}(\mathrm{KN})$ & $U \max (\mathrm{mm})$ \\
\hline 1 & 200 & 830 & 10.77 \\
2 & 400 & 1150 & 18.9 \\
3 & 300 & $>1200$ & 7.6 \\
\hline
\end{tabular}

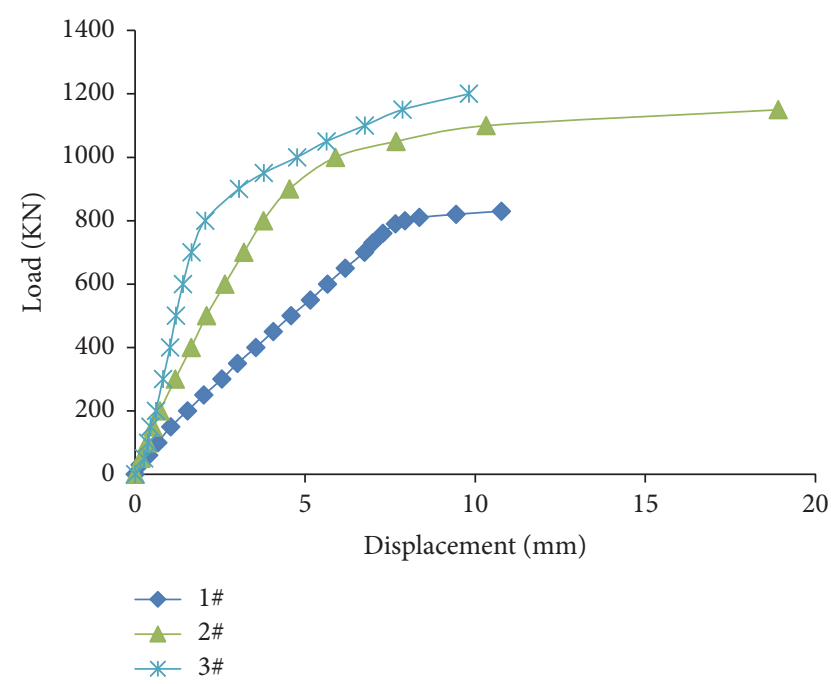

FIgURE 2: Load-displacement curve of the beams.

Displacement gauges were arranged in the support, $1 / 4$ points, and the mid-span. In each loading process, the corresponding load and displacement values were recorded synchronously.

\section{Test Results}

3.1. Summary of Load Capacity. The crack load (Vcr), ultimate load $(\mathrm{Vu})$, and the mid-span displacement (Umax) corresponding to the ultimate load of these three beams are shown in Table 4. The load-displacement curve is shown in Figure 2.

3.2. Summary of Crack Development Status. Three test Tbeams were carried out under $200 \mathrm{KN}, 500 \mathrm{KN}, 800 \mathrm{KN}$, $1000 \mathrm{KN}, 1100 \mathrm{KN}$, and $1200 \mathrm{KN}$. The results are shown in Table 5. The crack diagram of each beam is shown in Figure 3. 

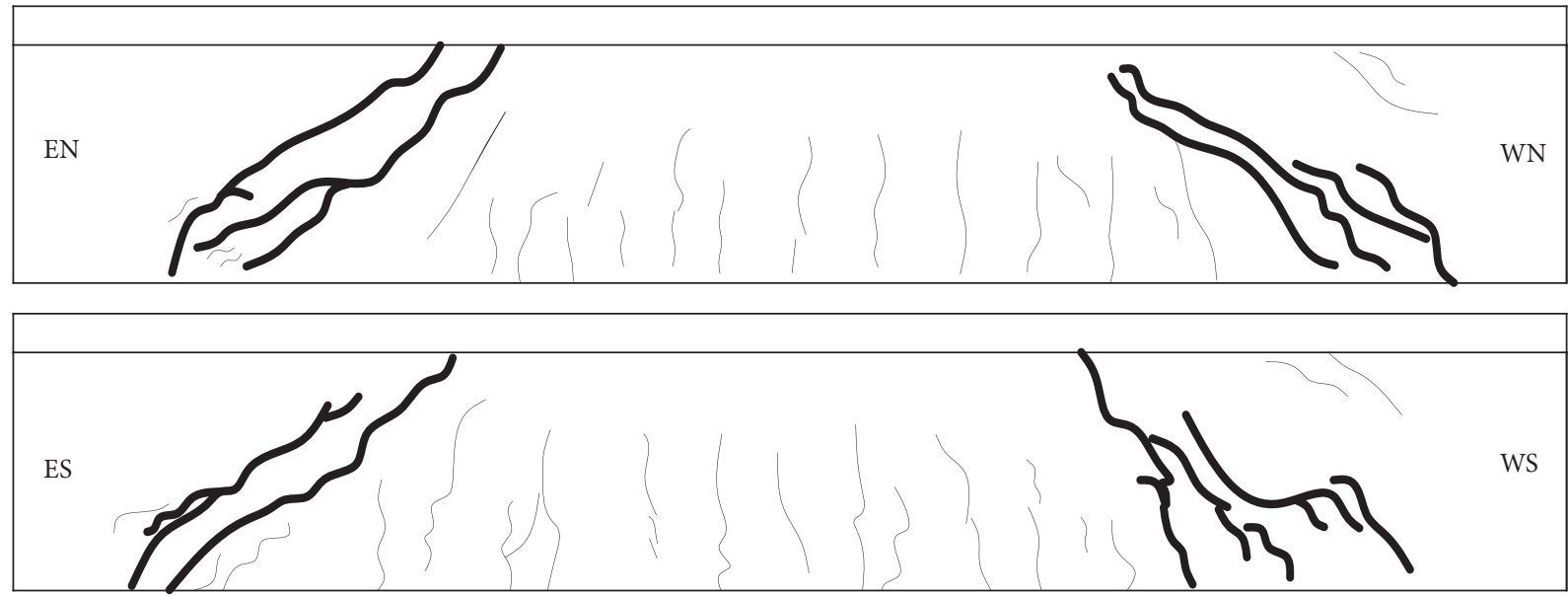

(a) Crack diagram of 1\# beam
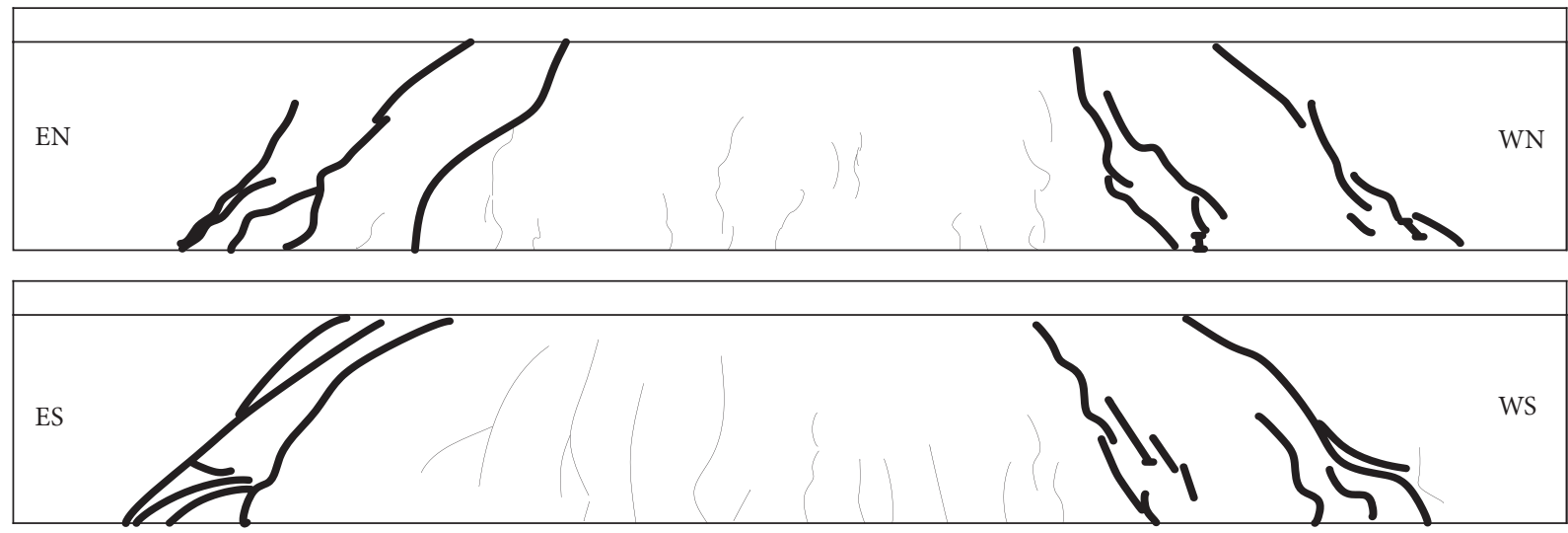

(b) Crack diagram of 2\# beam
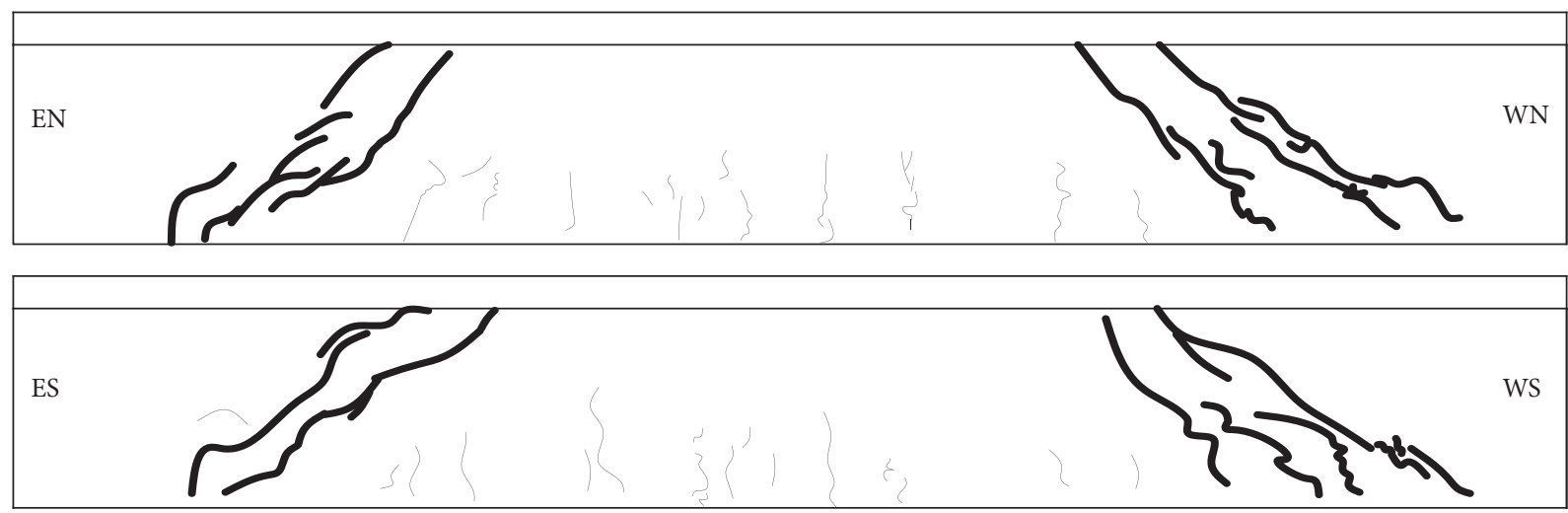

(c) Crack diagram of 3\# beam

Figure 3: Crack diagram of each beam.

TABLE 5: The development status of the maximum crack width (unit: $\mathrm{mm}$ ).

\begin{tabular}{lcccccc}
\hline Node & \multicolumn{6}{c}{ Load } \\
& $200 \mathrm{KN}$ & $500 \mathrm{KN}$ & $800 \mathrm{KN}$ & $1000 \mathrm{KN}$ & $1100 \mathrm{KN}$ & $1200 \mathrm{KN}$ \\
\hline 1 & 0 & 1.6 & 2.5 & - & - & - \\
2 & - & 0.2 & 1.5 & 3.31 & $>4$ & - \\
3 & - & 0.1 & 0.5 & 0.63 & 1.5 & - \\
\hline
\end{tabular}

\section{Finite Element Simulation}

4.1. Element Selection and Finite Element Model. When ANSYS was used for finite element analysis of reinforced concrete, a separate model was adopted. The concrete was simulated by Solid 65 element and steel bar was simulated by Pipe 59 element. The bond slip between the steel fiber and concrete was neglected.

This paper established the 1/2 T-beam model, which can not only reduce the calculation time but also avoid 


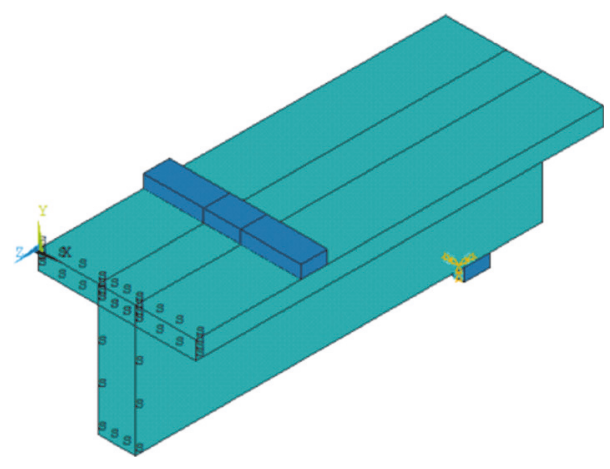

(a) Finite element solid model

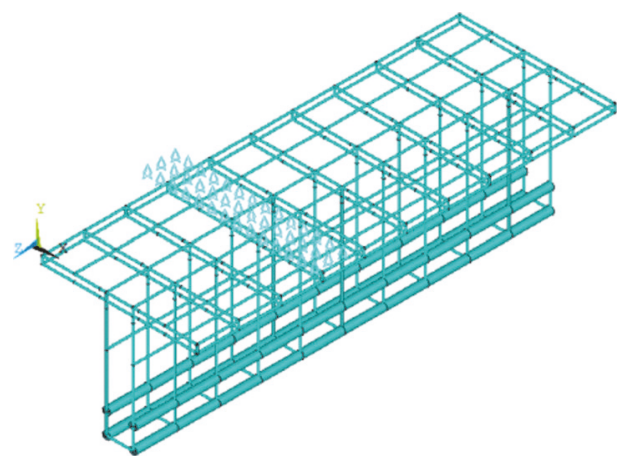

(b) Reinforced element model

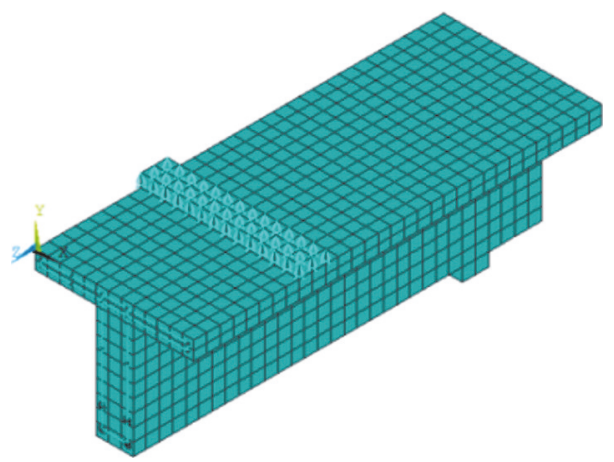

(c) Finite element mesh

FIgURE 4: ANSYS model.

terminating the calculation during calculation process due to too many warnings. In the finite element simulation, the stress concentration was avoided at the support and the loading point by adding an elastic pad. The ANSYS model is shown in Figure 4.

4.2. Selection of Constitutive Model of Materials. The doubleline strong hardening model (BISO) was used in the constitutive relation of the steel bar, and the formula about uniaxial compressive stress-strain curve of concrete [7] is (1) and (2). The constitutive relation of SFRC is modified on the basis of concrete [8-10], and the following formula (4) is used.

Constitutive relation of concrete is as follows:

Ascending stage is

$$
y=\frac{N x-x^{2}}{1+(N-2) x} .
$$

Descending stage is

$$
y=\frac{x}{\alpha(x-1)^{2}+x} .
$$

In the formula,

$$
\begin{aligned}
x & =\frac{\varepsilon}{\varepsilon_{c}}, \\
y & =\frac{\sigma}{f_{c}}, \\
N & =\frac{E_{0}}{E_{s}},
\end{aligned}
$$

where $f_{c}$ is compressive strength of concrete; $\varepsilon_{c}$ is peak strain associated with $f_{c} ; E_{0}$ is initial elastic modulus of concrete; $E_{s}$ is secant modulus at the peak strain.

Constitutive relation of SFRC is

$$
\frac{f_{c}}{f_{c}^{\prime}}=\frac{\beta\left(\varepsilon / \varepsilon_{0}\right)}{\beta-1+\left(\varepsilon / \varepsilon_{0}\right)^{\beta}} .
$$

In the formula,

$$
\begin{aligned}
\beta & =0.5811+1.93 \lambda_{f}^{-0.7406} \\
\lambda_{f} & =\frac{\rho_{f} l_{f}}{d_{f}},
\end{aligned}
$$

where $\rho_{f}$ is volume fraction of steel fiber, $l_{f}$ is steel fiber length, and $d_{f}$ is steel fiber diameter. 
TABLE 6: Cracking load and ultimate load of three test T-beams.

\begin{tabular}{|c|c|c|c|c|c|c|}
\hline Beam note & $\begin{array}{c}V \mathrm{cr}, \exp \\
(\mathrm{KN})\end{array}$ & $\begin{array}{c}\mathrm{cr}, \mathrm{cal} \\
(\mathrm{KN})\end{array}$ & $V \mathrm{cr}, \mathrm{cal} / V \mathrm{cr}, \exp$ & $\begin{array}{c}V \mathrm{u}, \exp \\
(\mathrm{KN})\end{array}$ & $\begin{array}{c}V \mathrm{u}, \mathrm{cal} \\
(\mathrm{KN})\end{array}$ & $V \mathrm{u}, \mathrm{cal} / V \mathrm{u}, \exp$ \\
\hline 1 & 200 & 213 & 1.065 & 830 & 810 & 0.976 \\
\hline 2 & 400 & 364 & 0.91 & 1150 & 1270 & 1.104 \\
\hline 3 & 300 & 411 & 1.37 & $>1200$ & 1420 & $<1.183$ \\
\hline
\end{tabular}

Note. $V \mathrm{cr}$,exp and $V \mathrm{cr}$,cal, respectively, represent the cracking load of the test and the finite element simulation; $V \mathrm{u}$,exp and $V \mathrm{u}$,cal, respectively, represent the ultimate failure load of the test and the finite element simulation.

\subsection{Comparative Analysis of Finite Element Results and Test Results}

4.3.1. Comparative Analysis of Load-Displacement Curve and Load Carrying Capacity. The comparisons of test data with ANSYS simulations are shown in Figure 5.

The cracking load and ultimate load of three test T-beams are shown in Table 6.

According to the 1-3\# beam, it can be seen that the loaddisplacement curve of the finite element is basically consistent with that of the test, and the gap of the failure load is not big. But the slope of the curve obtained by finite element method is slightly larger than that of the test chamber. The stiffness of the SFRC beam simulated by the finite element is slightly more than that of the test result. The main reason for this situation is the simulation of concrete inner and SFRC inner was ideal and with no flaw. In addition, due to the compacting process of beams in the actual process, the stiffness of the beam simulated by ANSYS is greater than that of test T-beam.

ANSYS simulation results showed that the test T-beam in the process of loading had experienced two stages, elastic and inelastic, along with the increase of load. The slope of the load-displacement curve was gradually reduced. The loaddisplacement curve obtained from the test also reflected the process of the stiffness degradation.

The volume fraction of steel fiber of $1 \#, 2 \#, 3 \#$ test T-beam, respectively, was $0,1.5 \%$, and $2 \%$. From Figure 5(d), it can been seen that the slope of the 2\# beam and 3\# beam in the elastic stage and the nonelastic stage is significantly greater than that of the 1 \# beam, which proves the adding of steel fiber can improve the stiffness and ductility of the concrete beam. In the nonelastic stage, the higher volume fraction of steel fiber is, the slower stiffness degradation of the concrete is. Figure 5(e) curves obtained from the test also reflect this characteristic.

From Table 6, it can be seen that the results of the cracking load and the ultimate failure load simulated by finite element analysis are not quite different from the tests result, and the ratio is close to 1 . With the incorporation of steel fiber, the ultimate bearing capacity has been significantly improved. And the higher the volume fraction of steel fiber, the higher the ultimate bearing capacity.

4.4. Crack Distribution and Comparative Analysis of Damage. From Table 6, the finite element simulation results showed that, in the aspect of cracking loads, the cracking load of the test T-beam increases with the increase of volume fraction of steel fiber, which reflected that the initial cracking of the steel fiber can be suppressed by the addition of steel fiber. However, the cracking load of $3 \#$ beam is smaller than that of 2\# beam, which could be caused by the uneven mixing of steel fiber.

The smeared crack model was used in ANSYS to simulate the distribution and development of cracks, with the lack of ability to simulate single fracture of crack width and crack development. From the crack distribution, it can be seen that the ordinary concrete beam cracks and SFRC beam cracks almost distributed in the whole beam section, and the results gained from half length of the beams were compared in Figure 6 . Shown by the comparison, the fracture distributions simulated by finite element are in a good conformation with the fracture distributions during actual test.

From the crack distribution, it can be seen that the main crack spacing of beam 1 is smaller than that of beam 2 and beam 3. In Figure 6, $\theta_{i}(i=1,2,3)$ represents the main crack development angle of each beam; $h_{i}(i=1,2,3)$ represents the cross crack length produced by each beam. Since main crack development angle $\theta_{1}$ of beam 1 is less than $\theta_{2}$ and $\theta_{3}$, it shows that the incorporation of steel fiber can cause the crack to be dispersed and avoid the damage caused by the stress concentration. In cross crack area, the crack length $h_{1}$ produced by beam 1 is smaller than $h_{2}$ and $h_{3}$, besides $h_{3}<h_{2}$, which reflects that the addition of the steel fiber can increase the bending crack resistance.

The crack width of beam 1 , beam 2 , and beam 3 is compared in Table 5 . The occurrence of cracking of beam 1 was the earliest, and the crack development speed was the fastest. Beam 2 and beam 3 almost simultaneously cracked, but, in the same load conditions, the crack width of beam 3 was smaller and the crack development speed was slower than beam 2 . In the elastic stage of beam 2 , the crack developed slowly, but, after the elastic stage, the crack developed quickly, which showed that the increase of volume fraction of steel fiber can improve the crack resistance of the concrete and delay the development of cracks. Because when volume fraction was greater than $2 \%$, it is difficult to blend steel fiber in concrete, so the study was not done.

\section{Conclusions}

Through the above test and finite element simulation analysis, the following conclusions can be drawn:

(1) The incorporation of steel fiber can improve the integral rigidity and ductility of concrete T-beam. In a certain range, the higher the volume fraction of steel 


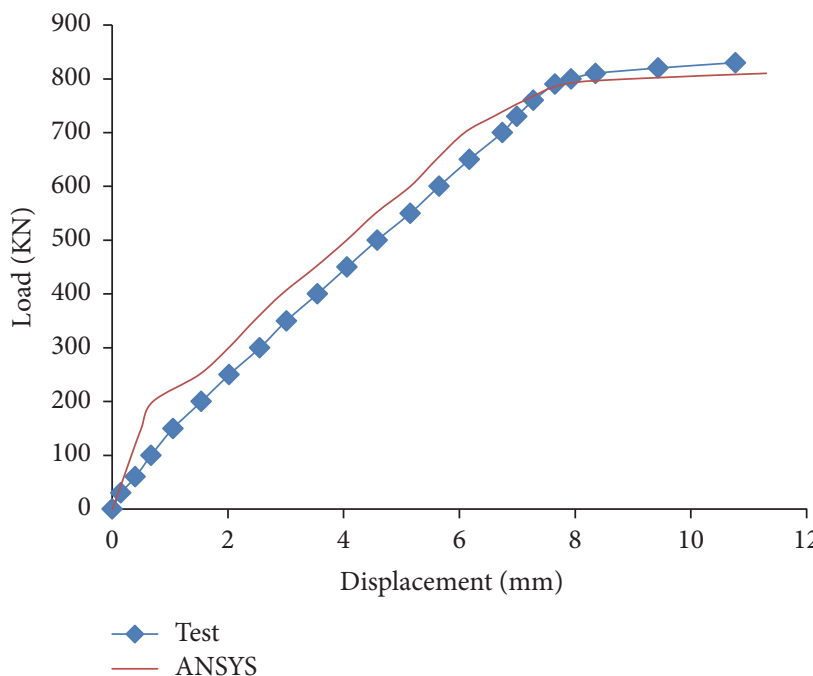

(a) 1\# beam comparison diagram

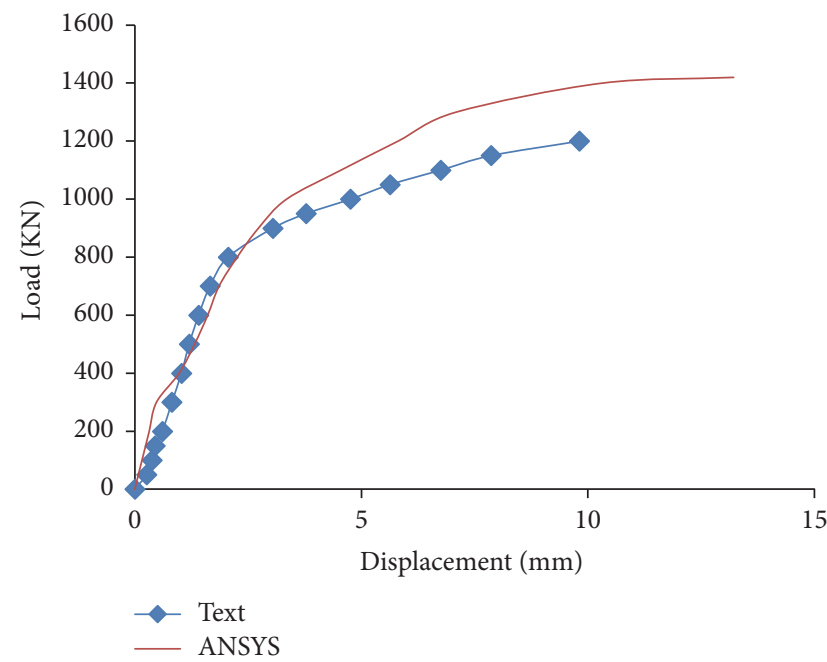

(c) 3\# beam comparison diagram

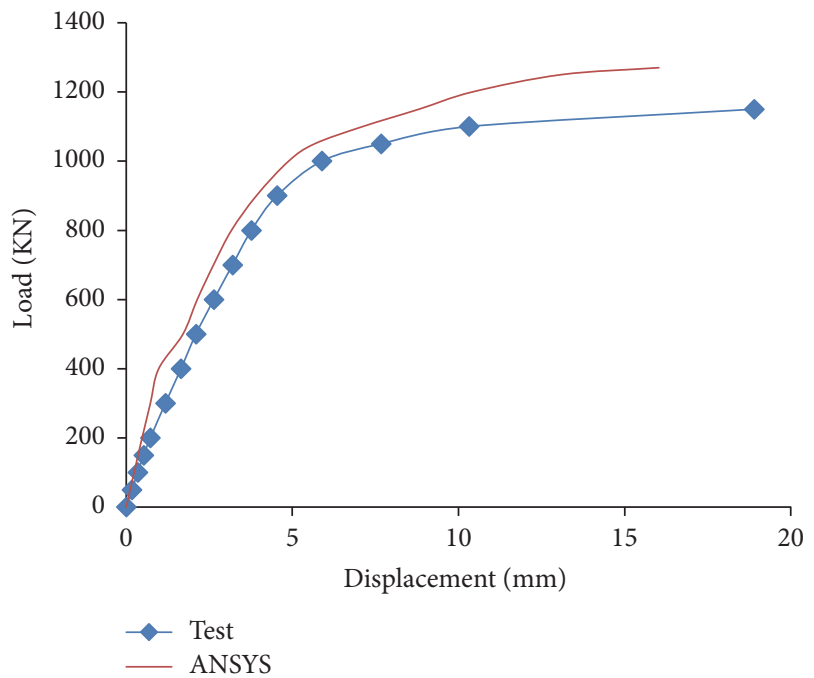

(b) 2\# beam comparison diagram

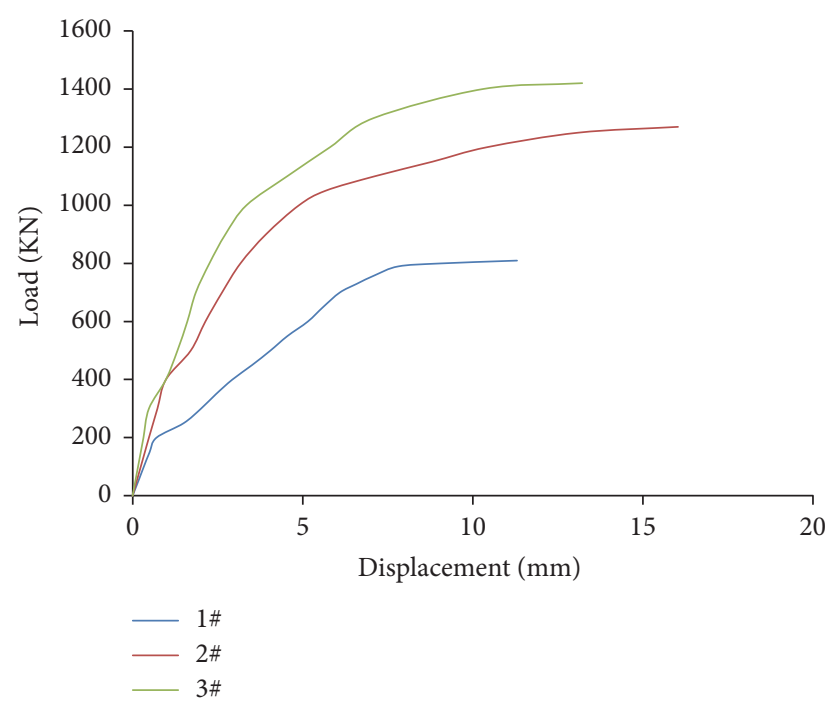

(d) Test results

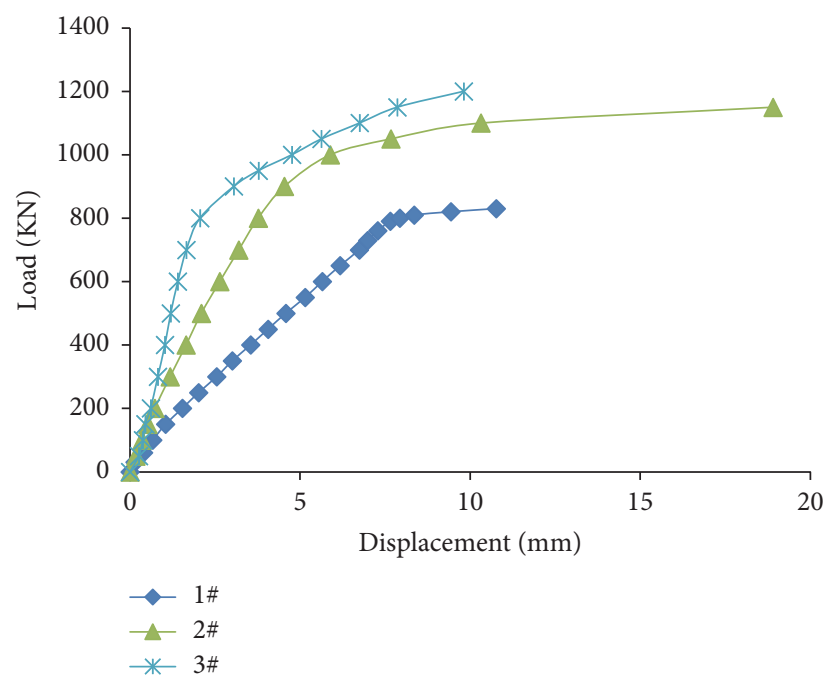

(e) ANSYS results

FIGURE 5: Comparison of the results of test with ANSYS simulation. 


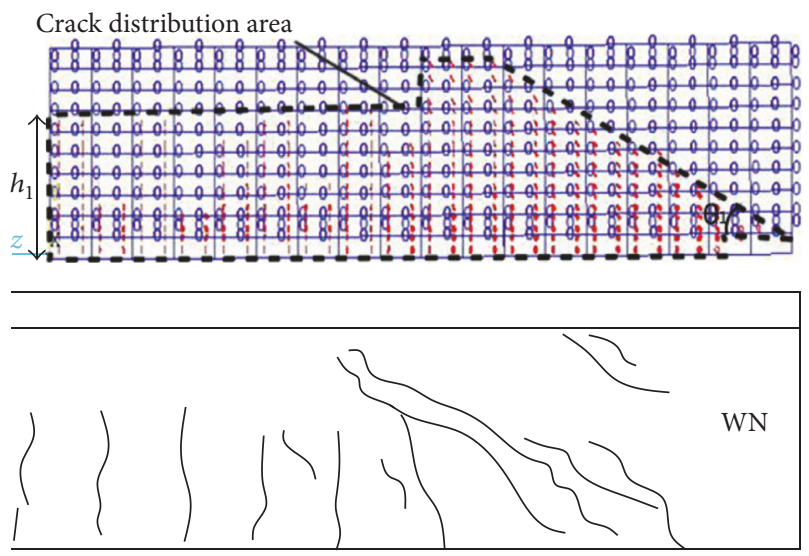

(a) Finite element simulation results and test results of 1 \# beam cracks

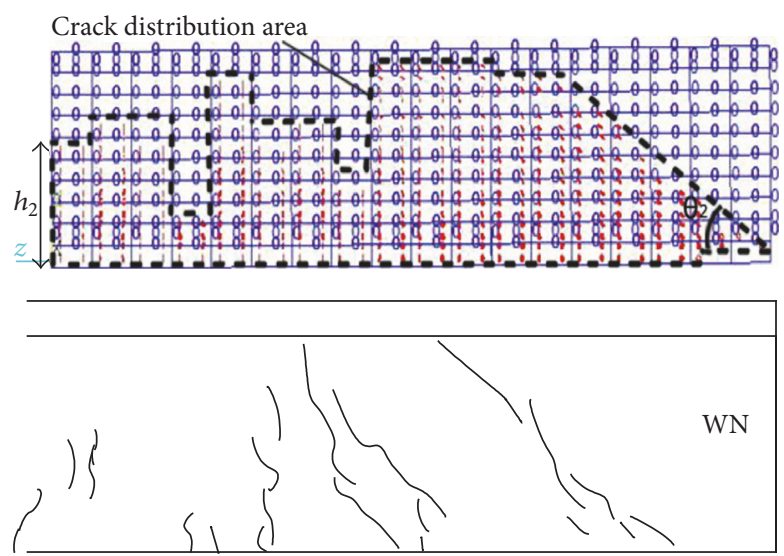

(b) Finite element simulation results and test results of 2\# beam cracks

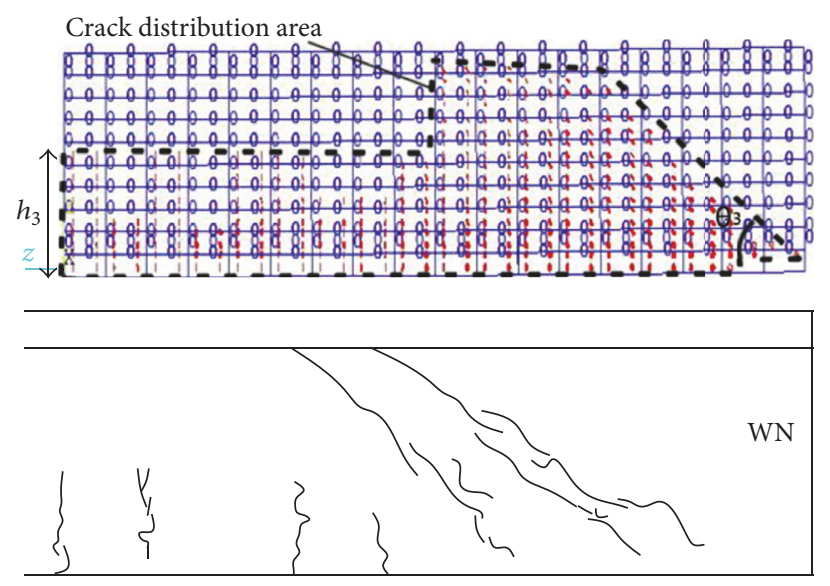

(c) Finite element simulation results and test results of 3\# beam cracks

FIGURE 6: Finite element simulation and test results of the cracks of each beam.

fiber is, the higher the integral rigidity is and the slower the stiffness degradation of T-beam is.

(2) With the same reinforcement ratio and shear span ratio, the higher volume fraction of steel fiber is, the higher the ultimate shear bearing capacity of the concrete T-beam is.

(3) The increase of volume fraction of steel fiber can delay the development of cracks and make the distribution of cracks more uniform and also improve crack resistance of the concrete T-beam when volume fraction was less than $2 \%$.

(4) Finite element analysis of SFRCT-beams by ANSYS is feasible, and the results obtained by ANSYS are in good agreement with test results. ANSYS can simulate the general trend of the crack and the crack distribution area of the T-beam by using the smeared crack model.

\section{Conflicts of Interest}

The authors declare that they have no conflicts of interest.

\section{Acknowledgments}

The research described in this paper was financially supported by the Jiangsu Province Key Laboratory of Structure Engineering, located in Suzhou University of Science and Technology.

\section{References}

[1] X. Sun, B. Diao, and Y. Ye, "Flexural behavior experiments of ultra-high performance concrete beams reinforced with steel bar and hybrid-fiber," Industrial Architecture, vol. 42, no. 11, pp. 16-21, 2012.

[2] Z. Y. Sun, Y. Yang, W. H. Qin, S. T. Ren, and G. Wu, "Experimental study on flexural behavior of concrete beams reinforced by steel-fiber reinforced polymer composite bars," Journal of Reinforced Plastics and Composites, vol. 31, no. 24, pp. 1737-1745, 2012.

[3] H.-Z. Zhang, C.-K. Huang, and R.-J. Zhang, "Experimental study on shear resistance of steel fiber reinforced high strength concrete beams," Journal of Harbin Institute of Technology, vol. 38, no. 10, pp. 1781-1785, 2006.

[4] J.-S. Cho, The Shear Behavior of Steel Fiber Reinforced Prestressed Concrete Beams without Shear Reinforcement, The University of Texas at Arlington, Arlington, Tex, USA, 2011. 
[5] B.-X. Shi, "Experiment study on fatigue characteristic of steel fiber reinforced concrete," Journal of Hebei University of Engineering (Natural Science Edition), vol. 25, no. 2, pp. 9-12, 2008.

[6] L. Wang, Study on the Properties of Ultra-Short Ultra-Fine Steel Fiber Reinforced Concrete, Chongqing Jiaotong University, Chongqing, China, 2011.

[7] Y. Li, X. Wang, and S. Chen, "Comparison of stress-strain curves of concrete under uniaxial compression," Highway Traffic Department, vol. 10, pp. 75-78, 2005.

[8] J. Qiu, "Study on nonlinear finite element analysis of steel fiber concrete structure," Concrete, no. 3, pp. 17-20, 2011.

[9] D. A. Fanella and A. E. Naaman, "Stress-strain properties of fiber reinforced mortar in compression," Journal of the American Concrete Institute, vol. 82, no. 4, pp. 475-483, 1985.

[10] B. Luccioni, G. Ruano, F. Isla, R. Zerbino, and G. Giaccio, "A simple approach to model SFRC," Construction and Building Materials, vol. 37, pp. 111-124, 2012. 


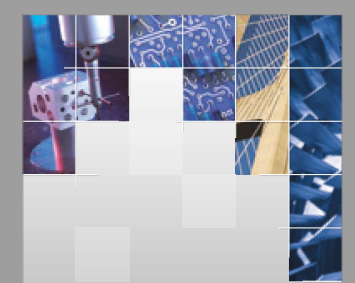

\section{Enfincering}
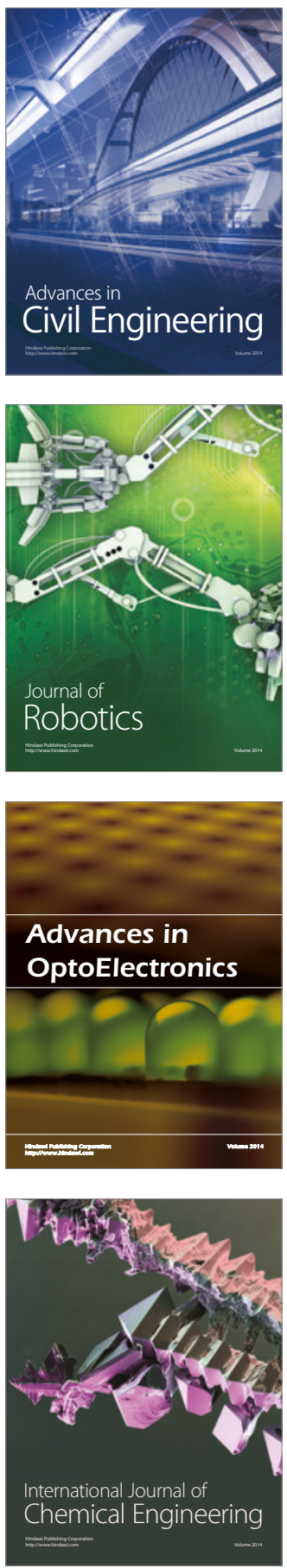

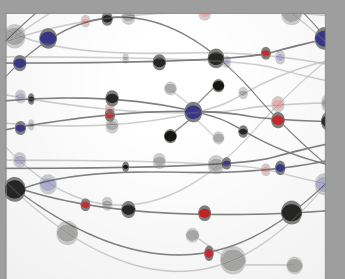

The Scientific World Journal

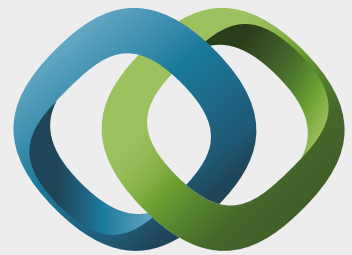

\section{Hindawi}

Submit your manuscripts at

https://www.hindawi.com
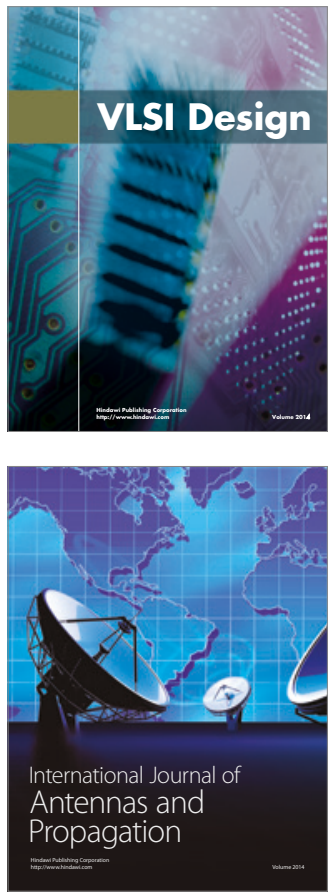

\section{Rotating}

Machinery
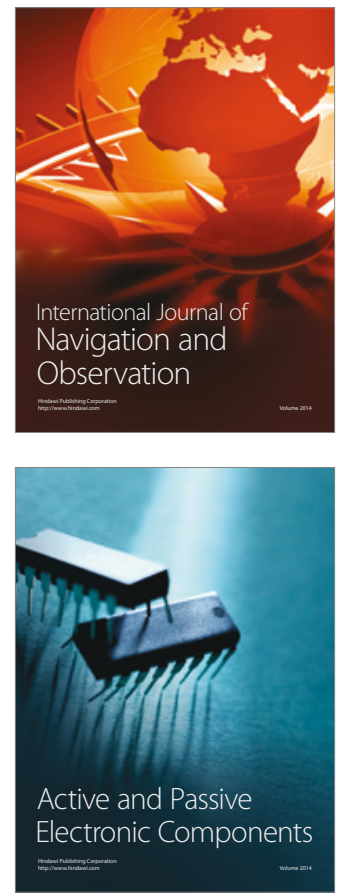
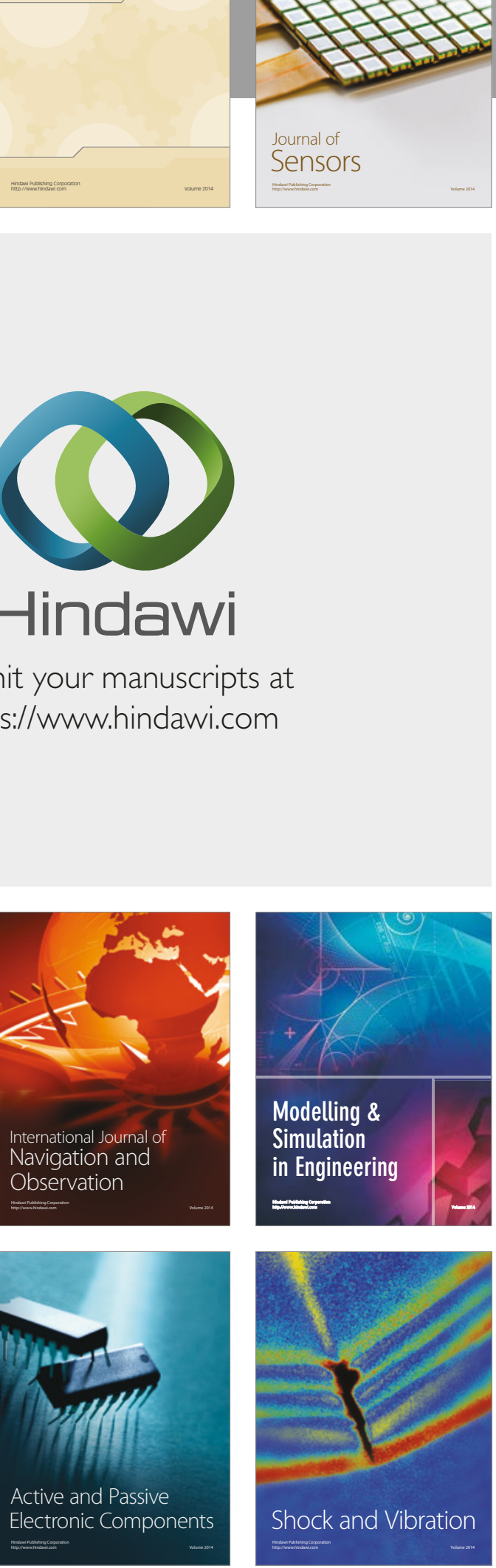
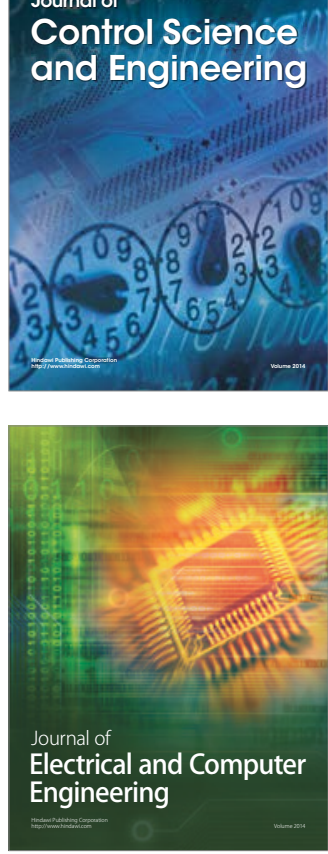

Distributed

Journal of

Control Science

and Engineering
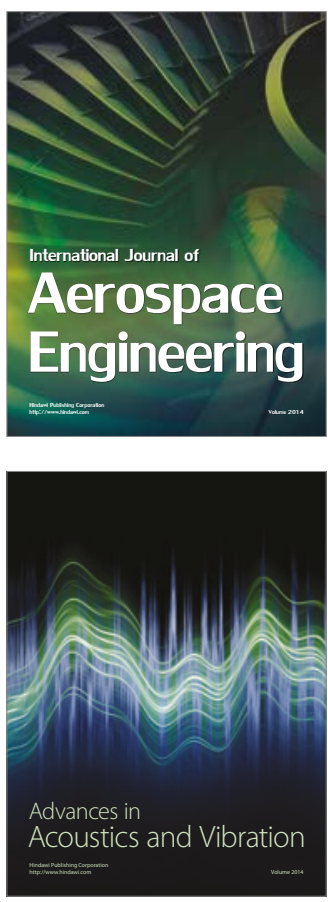

Sensor Networks 